\title{
OBSERVACIONES SOBRE ALGUNAS OBRAS DE PABLO VERONÉS Y DE SUS SEGUIDORES EN ESPAÑA (ALVISE BENEFATTO DEL FRISO, MICHELE PARRASIO) *
}

\author{
POR \\ JOSÉ MARÍA RUIZ MANERO
}

En este artículo se estudian tanto las obras conocidas en España de Alvise Benfatto del Friso y de Michele Parrasio como otras que se les atribuye por primera vez.

Palabras clave: pintura; Venecia; S. XVI; Veronés; Benfatto del Friso; Parrasio.

In this article the author discusses the works known in Spain by Alvise Benfatto del Friso and Michele Parrasio and also attributes some paintings to them for the first time.

Key words: painting; Venice; sixteenth century; Veronese; Benfatto del Friso; Parrasio.

Entre los cuadros de las antiguas colecciones reales pueden algunos atribuirse a Alvise Benfatto del Friso, autor del que acertadamente dijo Larcher Crosato que fue un «fedele imitatore del Maestro nella tematica, e non nello spirito» ${ }^{1}$.

Muy posiblemente, como piensa la misma Larcher, sea de su mano «Las bodas de Caná» (L. $127 \times 209 \mathrm{cms})^{2}$ (Fig. 1), cuadro conservado en el Museo del Prado y sobre el que la crítica no se ha manifestado unánime en cuanto a su atribución ${ }^{3}$. Resalta la estudiosa, además de

\footnotetext{
* Este artículo es la segunda parte del artículo «Observaciones sobre algunas obras de Pablo Veronés y de sus seguidores en España (I. Pablo Veronés)», publicado en Archivo Español de Arte, T. LXXV, 2002, n. ${ }^{\circ}$ 297, pp. 5-21.

${ }^{1}$ Larcher Crosato, L., «Note per Alvise Benfatto del Friso», Arte Veneta, 1976, año XXX, p. 108-109. Para más información sobre este pintor véase, además, idem, «La bottega di Paolo Veronese», en Nuovi studi su Paolo Veronese, Venecia, 1990, 259-261.

${ }^{2}$ Larcher Crosato,art. cit., 1976, p. 113-114.

${ }^{3}$ Museo del Prado. Inventario General de Pinturas. I La Colección Real, Madrid, 1990, p. 136, nº 453 (inv. act. n 494) (tanto en la ficha del inventario de 1857 como en la del inventario actualizado figura como obra de Pablo Veronés).

Tanto en las publicaciones antiguas sobre El Escorial como en los catálogos del Museo del Prado figura a nombre de Pablo Veronés. También la creyeron del maestro Caliari (1888), Lefort (1890) y Berenson (en 1932 y 1950, la consideraba obra tardía). Por su parte, Osmond (1927) la atribuyó con dudas a Pablo Veronés y Fiocco (1934) la creyó de taller (apud Pignatti, T. - Veronese. L'opera completa, Venecia, 1976, T. I, p. $192\left(\mathrm{n}^{\circ} \mathrm{A} 172\right)$ - , quien piensa que se debe a un seguidor). Marini R. (L'opera completa del Veronese, Milán, 1968, p. 134) la incluyó entre las obras que han sido atribuidas con autoridad a Pablo Veronés, pero que en la actualidad la crítica tiende a silenciar. El mencionado Berenson llegó considerarla obra juvenil del maestro, pintada bajo la influencia de Badile (opinión que figura en el archivo fotográfico del Museo del Prado en una nota manuscrita y que se recoge en el Catálogo de las pinturas del Museo del Prado, Madrid, 1985, p. 755 ). También en dicho archivo figura otra nota manuscrita que reza: «Van Dycke dice es ahora de taller o de escuela
} 
su colorido de tonos grisáceos que contribuye a potenciar el aspecto plano de la pintura, la incapacidad que muestra su autor en establecer una adecuada relación espacial entre el fondo arquitectónico y la mesa que ocupa casi toda la escena. Estilísticamente la sitúa cercana al seguro cuadro de Alvise de «Jesús y el centurión» (firmado y fechado en 1587), que se conserva en la iglesia del Angel Rafael de Venecia. Además de lo señalado por Larcher, quisiera añadir que también nos hablan de dicho pintor el preciosismo de su menudo y a veces geométrico trazo, la tendencia a ensimismar a los personajes, su cierta rigidez y falta de noble compostura, y la ausencia de los acompasados y ampulosos ritmos de Pablo Veronés.

Figura entre las pinturas compradas en Inglaterra por el conde de Fuensaldaña (posiblemente durante 1651) y enviadas a España: «En el Escorial ${ }^{4}$. Mas otra muy linda pieza a saver las bodas de Cana en Galilea figuras de $\mathrm{m}^{\circ}$. de $\mathrm{Pa}^{\circ}$. Veroneus fs. $700 . »{ }^{5}$. En 1657 la menciona Santos en la iglesia antigua de San Lorenzo de El Escorial: «Otros ay aqui de diferentes Autores, y Historias, ... no quiero ser cansado en referirlos todos.

Solo dirè de vno, que es de Paulo Veronès, de las Bodas de Canà de Galilea, donde Christo està obrando el milagro de la conuersion del agua en vino, que es muy digno de aduertir. .... Diòle à esta Casa el Rey Philipo Quarto, ...». Pocos años después debió trasladarse al Atrio de las Salas Capitulares, pues allí lo sigue citando el padre Santos en las ediciones de su libro de 1667,1681 y 1698, así como el autor de una relación anónima del siglo XVII sobre los cuadros del Escorial ${ }^{6}$. Ya en el siglo XVIII, la describen en el mismo lugar tanto Ximénez como Ponz ${ }^{7}$. El 1 de noviembre de 1809 fue trasladado de El Escorial a Madrid: «Núm 26 (caja) contiene: PABLO VERONÉS Las Bodas de Caná» ${ }^{8}$ y el 14 de mayo de 1813 del exconvento del Rosario a la Academia de San Fernando: «N. 140. Vn quadro de 6 palmos de alto por 10 de ancho. Representa Las bodas de Canaa; autor Pablo Veronés.» ${ }^{9}$. Al volver a El Escorial se le vuelve a colocar en la Antecámara de las Salas de Capítulos «8. Las bodas de Caná con figuras medianas, por Pablo Veronés.» ${ }^{10}$. En 1837 se trasladó al Museo del Prado ${ }^{11}$.

Cuenta el Museo de Bellas Artes de Granada con un «Calvario» $\left(\right.$ L. $131 \times 125$ cms.) ${ }^{12}$ (Fig. 2), depósito del Museo del Prado y también procedente de El Escorial, que igualmente se le

de Pablo Veronés». Ultimamente ha sido estudiada por Ruiz Gómez, L.(Catálogo de Pintura Veneciana histórica en el Real Monasterio de El Escorial, Madrid, 1991, pp. 156-157), quien no se decide a atribuirla a un pintor en particular y aporta muchos datos sobre su presencia en El Escorial durante los pasados siglos, y por Checa, F. (Tiziano y la monarquía hispánica, Madrid, 1994, p. 294-295), quien la considera obra del círculo veronesiano.

${ }^{4}$ Nota de don Gaspar de Haro, séptimo marqués del Carpio (Vergara, A., «The Count of Fuensaldaña and David Teniers: their purchases in London after the civil war», The Burlington Magazine, 1989, febrero, p. 129).

5 Vergara (art. cit., 1989, febrero, p. 132) identifica esta referencia con la pintura del Prado y comenta que en Museo del Prado. Catálogo de las Pinturas (Madrid, 1972) se dice que procede de la colección de Carlos I de Inglaterra, pero que sin embargo no figura en los inventarios de sus bienes. Recoge que el padre Santos la cita en la iglesia vieja de El Escorial.

${ }^{6}$ Santos, F., Descripcion breve del Monasterio de S. Lorenzo El Real del Escorial, Madrid, 1657, fol. 56v. Idem, idem, edición de 1667, fol. 69v-70. Idem, idem, edición de 1681, fol. 58. Idem, idem, edición de 1698 (apud Sánchez Cantón, F. J., Fuentes literarias para la Historia del Arte Español, Madrid, 1933, T. II, p. 293). Andrés, G. de, «Relación anónima del siglo XVII sobre los cuadros del Escorial», Archivo Español de Arte, 1971, n 173, p. 51.

7 Ximénez, A, Descripción del Real Monasterio de San Lorenzo del Escorial, Madrid, 1764, fol. 82-83. Ponz, A., Viaje de España, Madrid, 1788, T. II, Carta IV, n 28 (edic.Madrid, 1988, Vol. 1, p. 389).

${ }^{8}$ Hempel Lipschutz, I., «El despojo de obras de arte en España durante la Guerra de la Independencia», Arte Español, 1961, p. 244.

9 V.V., «Manuel Napoli y la colección de cuadros del exconvento del Rosario», Revista de Archivos, Bibliotecas y Museos, 1904, noviembre, p. 197.

${ }^{10}$ Bermejo, Fray D., Descripción artística del Real Monasterio de San Lorenzo del Escorial y sus preciosidades después de la invasión de los franceses, Madrid, 1820, p. 188.

11 Catálogo de las pinturas del Museo del Prado, Madrid, 1985, p. 755. En 1857 lo cita V. Poleró entre los cuadros que entonces se encontraban en el Prado procedentes de El Escorial (Catálogo de los cuadros del Real Monasterio de San Lorenzo, llamado del Escorial, en el que se comprenden los del Real Palacio, Casino del Príncipe y Capilla de la Fresnada, Madrid, 1857, p. 181).

${ }_{12}$ Depositado por O.M. de 27 de julio de 1970. (Museo del Prado. Inventario General de Pinturas. I..., Madrid, 1990, p. 134, $\mathrm{n}^{\circ} 447$ (inv. act. $\left.\mathrm{n}^{\circ} 496\right)$ ).

$A E A$, LXXVIII, 2005, 309, pp. 45 a 58 


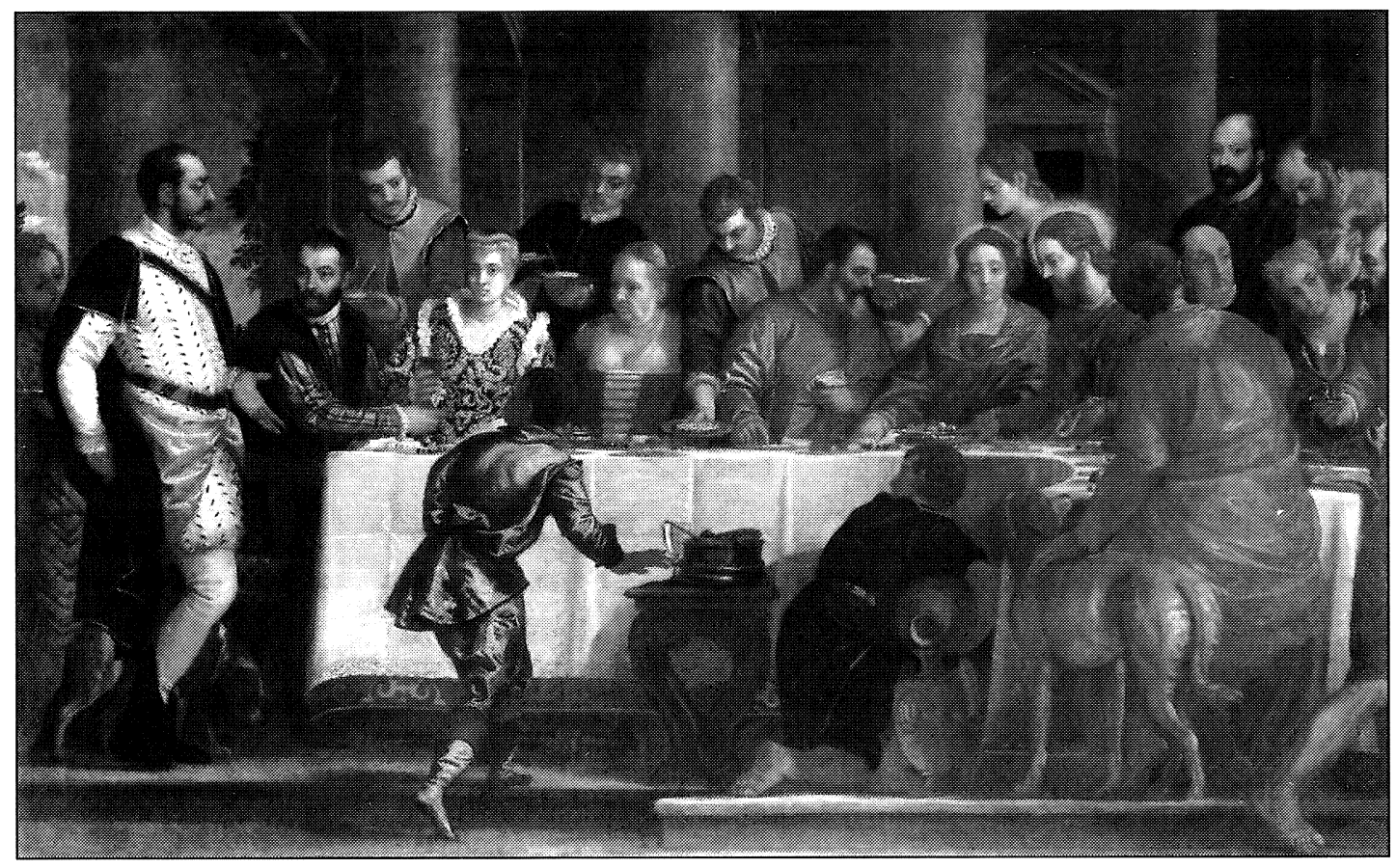

1

2
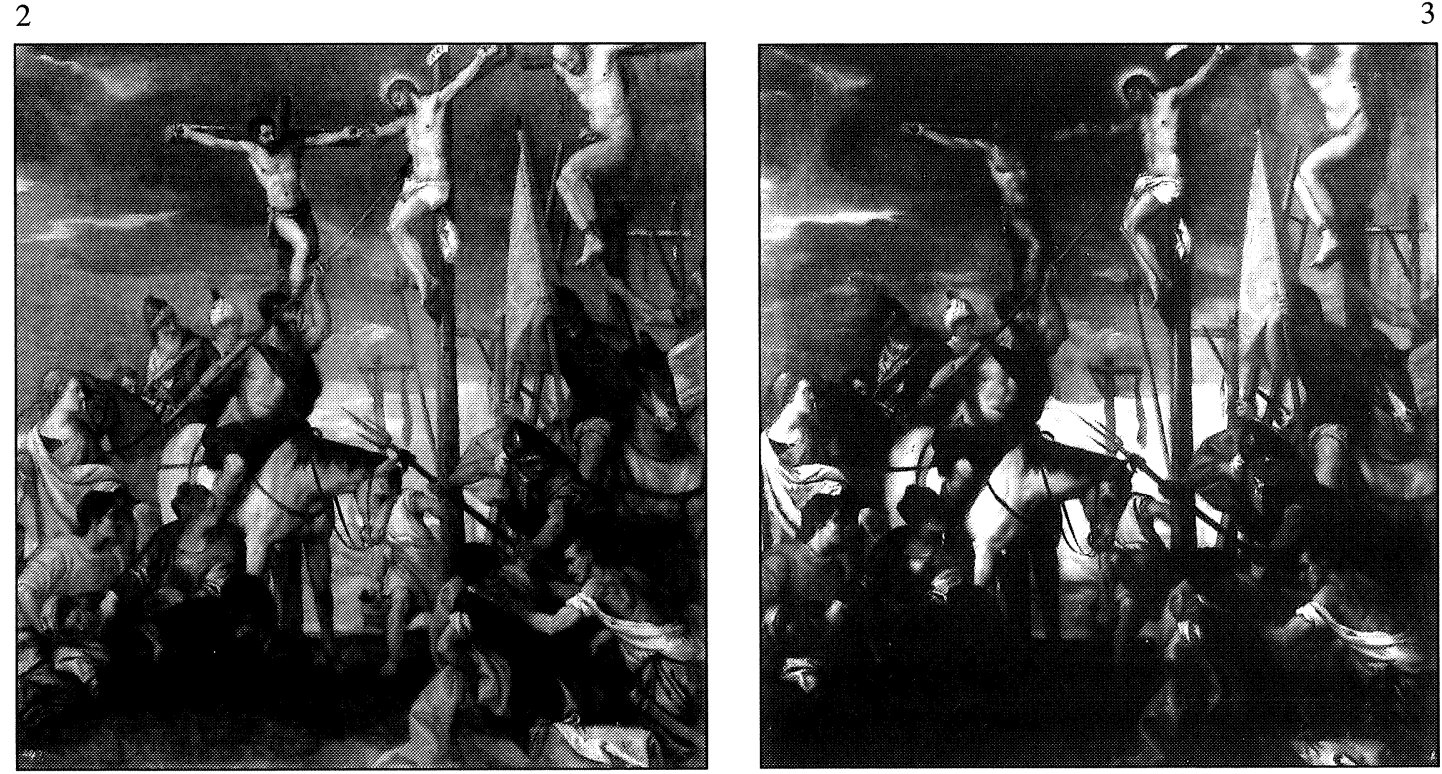

Fig. 1. Alvise Benfatto del Friso: Las bodas de Caná. Madrid. Museo del Prado.

Fig. 2. Alvise Benfatto del Friso: Calvario. Museo del Prado (Madrid). Cuadro depositado en el Museo de Bellas Artes de Granada.

Fig. 3. Alvise Benfatto del Friso (copia): Calvario. Madrid. Palacio Real. (Copyright $\odot$ Patrimonio Nacional).

$A E A$, LXXVIII, 2005, 309, pp. 45 a 58 
puede atribuir y sobre el que la crítica tampoco se ha manifestado unánime ${ }^{13}$. Su composición se relaciona muy estrechamente con el mundo de Pablo Veronés, ya que participa del gusto de éste por el juego de tensiones sabiamente contrabalanceadas que confieren riqueza compositiva y movimiento a lo representado. Incluso algunos de sus elementos aparecen en obras del maestro; obsérvese al respecto la desmayada figura de la Virgen, similar, como ya apuntó Ruiz Gómez, a la presente en la Crucifixión de la iglesia de San Sebastián (Venecia) —cuadro con el que comparte también la manera de disponer el paño de pureza de Jesús-, así como la posición del personaje que en el ángulo inferior derecho pelea con otro por la vestiduras de Cristo, tan semejante a la de la Santa Catalina que ofrece su mano al Divino Infante en el cuadro de su matrimonio místico que conserva el Christ Church College de Oxford ${ }^{14}$. Sin embargo, carece esta composición de la cadencia rítmica que desarrolla Pablo en sus obras autógrafas, apreciándose contrariamente una cierta tendencia a aunar en comprimidos grupos a los personajes.

Pero si, con las limitaciones apuntadas, la forma de disponer la escena recuerda en gran medida al maestro de Verona, su ejecución, en cambio, parece hablarnos de su discípulo Alvise. Frente a las amplias y certeras pinceladas de Veronés, muestra nuestra pintura unas pinceladitas menudas y nerviosas propias de la graciosa manera con la que del Friso labra las formas. Asimismo, la tendencia a afilar los rostros de los personajes, dotándoles de narices rectas y regulares, también parece propia de nuestro pintor; obsérvese, en particular, el perfil de San Juan, tan semejante al del criado situado detrás de Cristo en las «Bodas de Caná» (Museo del Prado, $\mathrm{n}^{\circ}$ 494). Por lo que respecta a su colorido podría decirse, con todas las limitaciones que impone la suciedad que la recubre, que resulta en términos generales más vivo que el utilizado por el mismo Alvise en su cuadro del Prado; obsérvese al respecto el amarillo claro del manto de la Magdalena o el rojo anaranjado de la túnica de San Juan.

Debido a su gran vinculación veronesiana, muy posiblemente haya que pensar que pudo ser realizada por nuestro pintor en el taller de Veronés durante la década de 1570, momento en el que Larcher Crosato sitúa las obras que cree de aquél realizadas con el estilo de éste ${ }^{15}$.

Afortunadamente, a pesar de encontrarse sucia y de observarse algunos repintes, especialmente en la figura del ladrón a la izquierda de Cristo ${ }^{16}$, su estado de conservación puede considerarse satisfactorio al no apreciarse pérdidas muy importantes de pintura.

Ya en 1657 lo cita el padre Santos en la Antesacristía del Monasterio de El Escorial: «Sobre las dos puertas, que la tienen en medio, ay dos Quadros de la Adoracion de los Reyes, y quando crucificaron à Christo Señor nuestro, de Paulo Verones, que como el de enmedio, se ajustan al ancho de las Puertas, que es quatro pies y medio, y el alto quatro (traducido a cen-

Se ha pensado que cabría la posibilidad de que estuviera firmado, ya que en el ángulo inferior izquierdo quizás fuera posible leer las siguientes letras «V. S.» (?) (cf. ficha conservada en el archivo fotográfico del Museo del Prado fechada en 1981 y firmada por Juan Gómez Segade; Espinos, A., Orihuela, M., Royo-Villanova, M., «»El Prado disperso». Cuadros depositados en Granada. I.», Boletín del Museo del Prado, 1983, T. IV, n 11, p. 116 (se menciona como obra del taller de Pablo Veronés)). No creo que quepa tal posibilidad, ya que a la vista del cuadro imagino que pudo tomarse por letras lo que únicamente son trazos que representan hierbas.

${ }_{13}$ Para Caliari, P. (Paolo Veronese, Roma, 1888, p. 380) y Gaya Nuño, J.A. («Notas al Catálogo del Museo del Prado» (El Prado disperso e inédito)», Boletín de la Sociedad Española de Excursiones, 1954, T. LVIII, p. 117) se debe a Pablo Veronés. Pignatti (op. cit., 1976, Vol. I, p. 184, n A117) la creyó obra tardía, en gran parte del taller (¿del Friso?). Ruiz Gómez (op. cit., 1991, pp. 151-152) la considera del taller de Veronés y recoge las menciones a la misma en publicaciones antiguas de El Escorial. Para Checa (op. cit., 1994, p. 291-292) se trata de obra de atribución discutida. Se sabe, por una nota conservada en el mencionado archivo del Museo del Prado, que Berenson opinó: «Paolo Veronese ¿copia antigua?».

14 Véase Pignatti, T. y Pedrocco, F., Veronese. L'opera completa, Milán, 1995, T. II, pp. 393-394 y $452-453$.

15 Véase Larcher Crosato, art. cit., 1976, pp. 106.

${ }^{16}$ La persona que la repintó se permitió cambiar la orientación de la inclinación de su cabeza, ya que la copia muy exacta de este cuadro conservada en el Palacio Real (véase estudio que se le dedica a continuación) la muestra ligeramente inclinada hacia el lado contrario.

AEA, LXXVIII, 2005, 309, pp. 45 a 58 
tímetros $111,2 \times 125,1$ ); de figuras medianas, pintadas de buen gusto, y disposicion» ${ }^{17}$, en donde durante la siguiente centuria lo siguen mencionando el padre Ximénez, el anónimo autor de una «Relación histórica de las pinturas de El Escorial por su orden riguroso de colocación hecha en 1776» —-son sus palabras: «6. Un Calvario de figuras chico O (original) P. Veronés»- y Ponz ${ }^{18}$. Durante la francesada debió abandonar el Monasterio, ya que figura entre los cuadros trasladados el 14 de mayo de 1813 del exconvento del Rosario a la Academia de San Fernando: «N. 17, Vn quadro que representa la Crucifixión del Señor, de vara y media en quadro (traducido a centímetros $125,25 \times 125,25$ ), original de Pablo Verones» ${ }^{19}$.

En la sacristía de la capilla del Palacio Real de Madrid se cuenta con una copia muy literal (L. $130 \times 124 \mathrm{cms})^{20} \mathrm{del}$ «Calvario» de Granada (Fig. 3), la cual incluso reproduce su colorido, aunque con tonos menos vivos. Muestra, sin embargo, con respecto a éste una tendencia a la simplificación del plegado de los paños, una pincelada, aunque suelta, menos viva y ágil, y una cierta acentuación del juego de luces y sombras, todo lo cual nos hace pensar que pudiera ser de fecha posterior al siglo Xvi. Se sabe que perteneció al Marqués de Salamanca ${ }^{21}$. Afortunadamente, aunque sucia, se encuentra en buen estado de conservación.

En el Escorial se conserva un cuadro de la «Predicación de San Juan Bautista en el desierto» (L. $156 \times 262$ ) 22 (Fig. 4), de indudable sabor veronesiano, que cuenta además con elementos compositivos muy típicos del maestro -obsérvese al respecto el gusto por la representación de figuras contrapuestas-, lo que lleva a pensar que no se debe excluir que su autor se basara para realizarlo en una idea suya. Sin embargo, puede observarse que la disposición de la escena carece de las serenas cadencias típicas del pintor de Verona. Sin duda su mal estado de conservación no facilita su atribución. Con todo, cabe suponer que se trata de obra de su taller y que, de sus discípulos, quizás sea Alvise del Friso al que con más probabilidades se le pueda atribuir, pues sus personajes muestran una cierta rigidez en sus movimientos y un ensimismamiento introspectivo que parecen hablarnos de él. Asimismo, sus pinceladas, a veces quebradas y nerviosas, también nos lo recuerdan. Por lo que respecta a su colorido, bajo la suciedad que lo recubre, se adivinan tonos muy hermosos y vivos; piénsese en el bello amarillo de los ropajes de la mujer que abraza a un niño o en el rosa delicado de la capa del personaje que apoya su mano izquierda en un árbol . En el caso de que, como creemos, pertenezca a Alvise, por su indudable vinculación veronesiana debería situarse su ejecución alrededor de 1570 , momento en que, como se ha dicho, Larcher Crosato considera que pudo realizar obras completas en el estilo del maestro ${ }^{23}$.

\footnotetext{
${ }^{17}$ Santos, op. cit., 1657 , fol. $42 \mathrm{v}$.

En una relación anónima del siglo XVII sobre los cuadros de El Escorial se cita, en el lugar que le asigna el padre Santos, un «Lavatorio» de Veronés. Como bien ha sido puesto de manifiesto por Andrés (art. cit., 1971, $\mathrm{n}^{\circ} 173$, p. 56), aunque resulte equivocado el asunto, sin duda debía tratarse de nuestra pintura.

${ }^{18}$ Ximénez, op. cit., 1764, fol. 288. Curiosamente Vega, A. («Relación histórica de las pinturas de El Escorial por su orden riguroso de colocación hecha en 1776», Documentos para la Historia del Monasterio de San Lorenzo, 1962, T. V, p. 247), quien publica la mencionada relación, dice a propósito de este cuadro: «Desaparecido y llevado a Francia». Ponz, op. cit., 1788, T. II, Carta III, nº 38 (edic. Madrid, 1988, Vol. I, p. 362).

19 V.V., «Manuel Napoli y la colección de cuadros del exconvento del Rosario», Revista de Archivos, Bibliotecas y Museos, 1903, noviembre, p. 376. En 1857 Poleró (op. cit, p. $181\left(\mathrm{n}^{\circ} 447\right)$ ) lo cita, como obra de P. Veronés, ya en el Museo del Prado.

${ }^{20}$ Pérez Sánchez ( «La pintura en las nuevas salas del Palacio de Oriente», Reales Sitios, 1968, nº 16, p. 38 ) puso de manifiesto la directa vinculación de su composición con Veronés y supuso que pudiera tratarse de obra de uno de sus imitadores, quizás su hijo Carletto.

${ }^{21}$ Agradezco al recordado D. Juan Martínez, que fue conservador del Patrimonio Nacional, que me comunicara que lleva el cuadro una nota pegada al dorso que lo prueba.

En su ángulo inferior izquierdo figura la siguiente inscripción «MB 5», en crema.

${ }_{22}$ Véase Checa, op. cit., 1994, p. 292 (recoge menciones del padre Santos. La considera obra de Pablo Veronés).

${ }^{23}$ Véase Larcher Crosato, art. cit., 1976, T. XXX, p. 106.
} 
Entre las obras de Pablo Veronés hoy perdidas, Pignatti y Pedrocco mencionan un «S. Giovanni che predica nel deserto», que Boschini (Le Minere della Pittura..., 1664, p. 346) señalaba en la iglesia de Santa Maria dell'Umiltà alle Zattere de Venecia ${ }^{24}$. Asimismo, se sabe por Ridolfi que, entre los cuadros de Pablo Veronés comprados por «Il Signor Vice Conte Basilio Feilding Inglese, poch' anni sono Ambasciatori à Venetia», se encontraba un cuadro de «San Giouanni predicante alle turbe» ${ }^{25}$. Al no tenerse hoy noticia de ninguna de estas dos obras, cabe la posibilidad de que una de ellas fuera la hoy conservada en El Escorial.

Siempre ha estado en El Escorial desde que el padre Santos lo describiera en 1657 en la Antesacristía: «... otro de Paulo Verones, de la predicacion de S. Iuan, ... Està el Bautista en el Desierto, significando muy al natural, la eficacia del espiritu, que le mouia à procurar con su enseñanza, y doctrina la salud de las Almas. Los que salian à oirle, se vèn, como suspendidos y robados de su voz; vnos en pie, otros sentados, ò à la sombra de los arboles, ò en las peñas, que se descubren en el Pays con mucha variedad. Dà este Lienço no poco que aduertir à los curiosos» ${ }^{26}$.

Por último, quisiera dejar constancia de que en el inventario de 1655 del marqués de Leganés se cita un cuadro no localizado del mismo asunto: «otra pintura de bara y ochaua en quadro (traducido a centímetros 94 x 94), la predicazion de san Juan, con muchas figuras arrimadas a unas peñas y arboledas, de Paulo belones. (sic), en tabla, 400 (reales, se entiende)» ${ }^{27}$.

Poca atención le ha dedicado la crítica a Michele o Michieli Parrasio, pintor que se valió de dibujos de Pablo Veronés para la realización de sus obras y del que desde época antigua han figurado cuadros suyos en España ${ }^{28}$.

El Museo del Prado conserva dos de muy distinto carácter. El primero, «La Alegoría del Nacimiento del infante don Fernando, hijo de Felipe II», ejemplo de pintura de celebración, en donde se recurre a la alegoría para ensalzar el nacimiento de un príncipe, y el segundo, «Cristo yacente adorado por el Papa San Pío V», muestra del arte al servicio de la devoción privada.

El significado de los elementos presentes en la «La Alegoría del Nacimiento del infante don Fernando, hijo de Felipe II» ${ }^{29}$ (L. $182 \times 223$ cms.) (Fig. 5) nos lo explica el mismo Parra-

\footnotetext{
${ }^{24}$ Pignatti y Pedrocco, op. cit., 1995, T. II, p. 538.

${ }_{25}$ Ridolfi, C., Le Meraviglie dell'Arte. Ovvero le vite degli Illustri Pittori veneti e dello Stato, op. cit., 1648, Parte prima, p. 321.

${ }^{26}$ Santos, op. cit., 1657, fol. 43

Se sigue citando, siempre como obra de Veronés y en el mismo lugar, en una relación anónima del siglo XVII sobre los cuadros del Escorial (Andrés, art. cit., 1971, $\mathrm{n}^{\circ}$ 173, p. 57), así como en el siguiente siglo en una relación histórica de las pinturas de El Escorial por su orden riguroso de colocación hecha en 1776 (Vega, op. cit., 1962, T. V, p. 246) y en los libros de Ximénez (op. cit., 1764, p. 289) y de Ponz (op. cit., 1788, T. II, Carta III, nº 38 (edic. 1988, Vol. I, p. 362)) . En 1820 Bermejo (op. cit., p. 246) lo menciona en la celda prioral: «un lienzo de mas de diez pies de ancho apaisado, en que se expresa San Juan Bautista en el desierto predicando á varias gentes que salian á oirle, de Pablo Veronés.» Poleró (op. cit., 1857, p. 68) lo cataloga, con el número 210, como obra de la «Escuela de P. Veronés».

${ }^{27}$ López Navio, J., «La gran colección de pinturas del Marqués de Leganés», Analecta Calasanctiana, 1962, p. 284.

${ }^{28}$ Sobre Michele Parrasio véanse Ridolfi (op. cit., 1648 (edición von Hadeln), 1924, Vol. II, p. 137- 138), Bryan, M. (Dictionnary of Painters and Engravers, Biographical and Critical, Londres, 1889, Vol. II, p. 254) y Hadeln, D.F. von («Parrasio Michele», Jahrbuch der Königlich preussischen Kunstsammlungen 33, (1912), pp. 149-72, cf. Cocke, R., Veronse Drawings. A catalogue raisonné, Londres, 1984, p. 173).

${ }^{29}$ Museo del Prado. Inventario General de Pinturas. I..., Madrid, 1990, p. 200, no 710 (inv. act. $n^{\circ} 479$ ) (en la ficha del inventario de 1857 figura como obra de «Veronés (Carlos)» y en la ficha del inventario actualizado como de «Michele Parrasio»).

Véanse también G. Fiocco (Paolo Veronese, 1528-1588, Bolonia, 1928, p. 159 y fig. 108), E. Lafuente Ferrari (El Prado. Escuela italiana y francesa, Madrid, 1977, p. 207 y reproducción en p. 212), D. Angulo Iñiguez (Museo del Prado. Pintura italiana anterior a 1600, Madrid, 1979, pp. 205-206), F. Checa (Felipe II mecenas de las artes, Madrid, 1992, p. 192 y op. cit., 1994, p. 312). Figura en el Catálogo de la Exposición «Felipe II. Un monarca y su época», Valladolid, 1998$1999, \mathrm{n}^{\circ}$ de cat. 12 y se reproduce en Menéndez Pidal,R., Historia de España, Tomo XIX. España en tiempos de Felipe II, Vol. II, 1958, fig. 112 (en la página 133).
}

$A E A$, LXXVIII, 2005, 309, pp. 45 a 58 

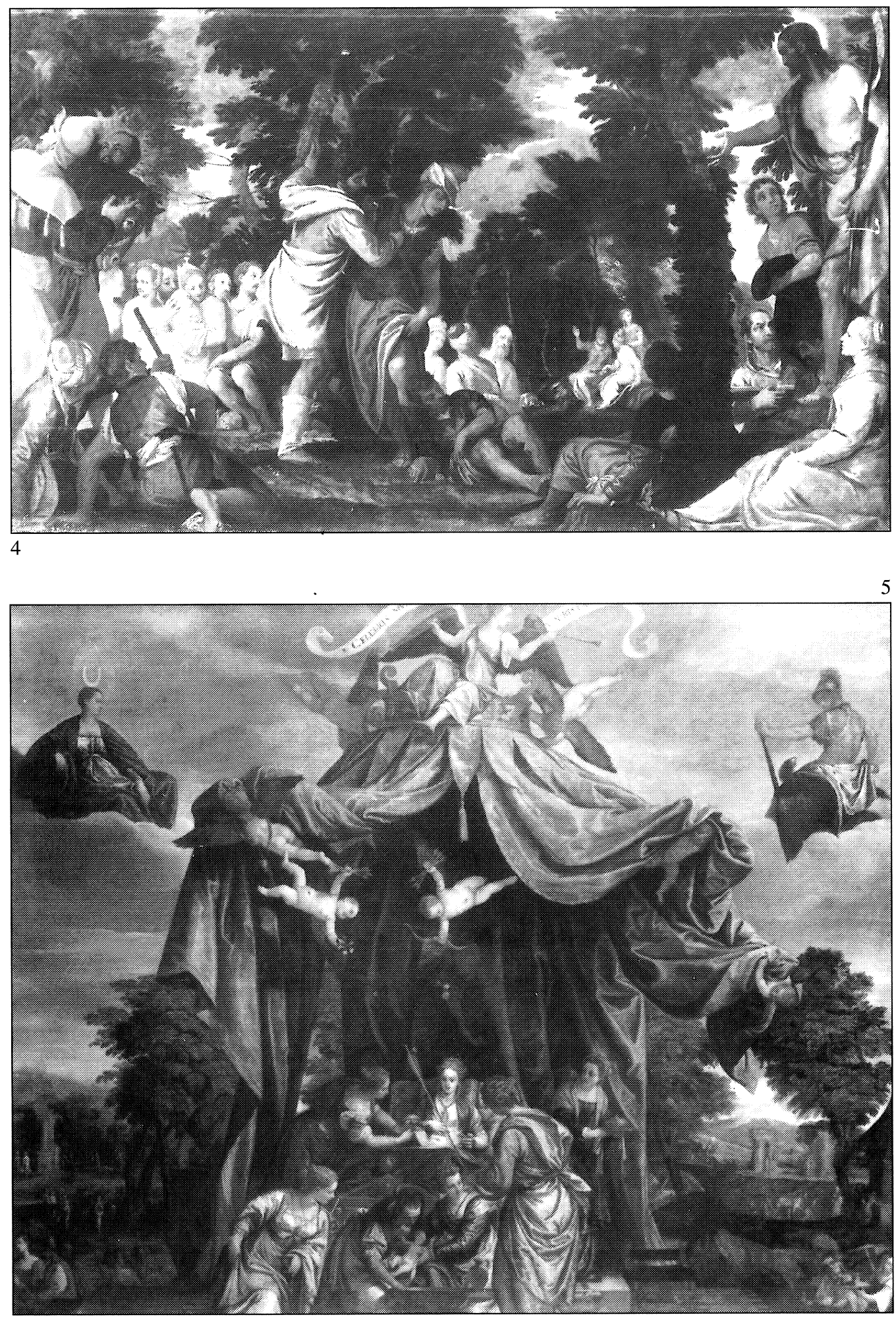

Fig. 4. Alvise Benfatto del Friso: Predicación de San Juan Bautista en el desierto. El Escorial (Madrid). Monasterio (Copyright $\odot$ Patrimonio Nacional).

Fig. 5. Michele Parrasio: La alegoría del nacimiento del infante don Fernando, hijo de Felipe II. Madrid. Museo del Prado. 
sio en la carta, fechada el 20 de agosto de 1575, con que acompañó su envío a Felipe II: «...e havendo osservato il tempo del nascimento che fu il Lunedi notte, venendo il Martedj (piénsese en las figuras de la Luna y de Marte que figuran en la parte superior del cuadro), ho voluto mostrare sotto a che pianetti é nata tanta altezza appogiata alle due Aquile segno Imperiale, che per una lunga successione d'Imperio s'é fermato in casa d'Austria. Apparisce sopra il padiglione una stella fuor delle nubi figurata per il gran príncipe che finalmente fuor delle nuvole della sterilitá, apparse al mondo sotto al padiglion del cielo, a cui fa capello il Zodiaco, mostrando, che tutti i segni celesti sono fautori di si meraviglioso e desiato parto. La fama poi, che siede di sopra, chiama con la sua tromba tutte le provincie ad honorar il nato principe; onde altre portando scettri e corone; i altre oro e geme; io figurato nella provincia d'Italia, vengo con somma humiltá di core a farle dono della presente pittura....» ${ }^{30}$.

La elegante y acompasada manera de relacionar las figuras de la escena principal recuerda mucho al maestro de Verona, quien amó los ritmos amplios y cadenciosos. Sin embargo pertenece totalmente a Parrasio el reducir su mundo a una escala de figuras diminutas, estilizadas y graciosas, pero desprovistas de serena nobleza. Se diría que Parrasio se adueñó de lo que de grácil y delicado tiene el arte de Veronés, sin ser capaz de asimilar su aspecto más noble y elevado. En cuanto al paisaje, hecho con pinceladas cortas y minuciosas, muestra un claro sabor flamenco. Por su parte, Meijer opina que tanto la composición como la realización de algunas figuras recuerdan tanto a Pablo que es lícito suponer su intervención o al menos la de alguno de sus asistentes y que, en cambio, el paisaje es obra de Paolo Fiammingo ${ }^{31}$.

Se sabe que la ofreció su autor a Felipe II para celebrar el nacimiento del infante don Fernando, quien nació el 5 de diciembre de 1571, fue jurado Príncipe heredero el 31 de mayo de 1573 y murió el 18 de octubre de 1578. En la mencionada carta Parrasio se disculpa de la tardanza en enviarla con las siguientes palabras: «La qual molto prima havrei mandata, se la fortuna mia, che gran tempo m' ha travagliato, me l' havesse permesso: ma non prima ho sospirato, che ho dato l'ultima mano all'opera...» ${ }^{32}$.

En el inventario de los bienes que Antonio Pérez tenía en La Casilla (fechado el 21 de mayo de 1585) figura: «En la primera Sala ques en subiendo La/ escalera de piedra ay Lo que abaxo se contiene/ Un quadro grande del parto de Venus nacim ${ }^{\circ}$ de/ cupido con su marco» ${ }^{33}$, cuadro que cabe la posibilidad bien que corresponda al nuestro, ya que Felipe II pudo regalarlo a Pérez poco después de recibido, bien al que se cita en la colección Madrazo y que se especifica más adelante. En 1701 se encontraba, sin duda, en el Palacio del Buen Retiro, exactamente en la Pieza de Consultas de Muerte: «Una Pinttura de tres Varas menos quarta de largo

\footnotetext{
30 Allende-Salazar, J. y Sánchez Cantón, F. J.(Retratos del Museo del Prado. Identificación y Rectificaciones, Madrid, 1919, p. 93) quienes publican íntegramente la carta -que confiesan fue dada a conocer por Constance J. Foulkes en el número de octubre de 1912 del Monatshefte für Kunstwissenchaft- e identifican la pintura allí citada con el cuadro del Prado.

${ }^{31}$ Meijer, B. W., «Paolo Fiammingo reconsidered», Overdruk uit de Meddelingen van het Nederlands Institut te Rome, XXXVII, 1975, pp. 12-13.

32 Allende-Salazar y Sánchez Cantón, op. cit., 1919, pp. 93-94.

Sarrablo Acuareles («La cultura y el arte veneciano en sus relaciones con España, a través de la correspondencia diplomática de los siglos XVI al XVIII», Revista de Archivos, Bibliotecas y Museos, 1956, T. LXII, p. 661) piensa que el homenajeado es el príncipe Carlos Lorenzo, nacido en Galapagar el 12 de agosto de 1573 y que ya había fallecido el 9 de julio de 1575 .

A pesar de que medien muchos años entre el nacimiento del infante Fernando y el envío del cuadro de Parrasio, pienso con Allende-Salazar y Sánchez Cantón que es éste el infante celebrado, ya que algunos pasajes de la mencionada carta parecen hacer alusión a un príncipe heredero de la corona, lo que nunca fue Carlos Lorenzo: «Nella cómune allegrezza de tutta la Christianitá c'ha fatto segno di molta letitia nel nascimento del gran Principe de Spagna,..............Apparisce sopra il padiglione una stella fuor delle nubi figurata per il gran príncipe che finalmente fuor delle nuvole della sterilitá, apparse al mondo... La fama poi, che siede di sopra, chiama con la sua tromba tutte le provincie ad honorar il nato principe: onde altre portando scettri e corone; i altre oro e geme .....»

${ }^{33}$ Delaforce, A., «The Collection of Antonio Pérez, Secretary of State to Philip II», The Burlington Magazine, 1982, diciembre, p. 750.
}

$A E A$, LXXVIII, 2005, 309, pp. 45 a 58 
y dos y quarta de alto (traducido a centímetros $188 \times 229,5$ ) del Partto de Benus Como Constta de Vn Rotulo que tiene enzima de vn Pabellon Original de Pablo Berones Con marco negro tassada en Ziento y Cinquenta Doblones ......9.000» ${ }^{34}$. Se sigue citando, con palabras muy semejantes y con el número 260, en el inventario de dicho Palacio de $1789^{35}$. En 1833 ya había sido trasladada a su sede actual, ya que figura en el inventario general de dicho año de los cuadros de S. M. existentes en la Galería del Real Museo: «430- Nacimiento de un Principe o del Amor - Pablo Verones- 30.000».

En la colección de Don José de Madrazo se cataloga a nombre de Pablo Veronés una obra , procedente de la Casa de Altamira, que debió de ser réplica o copia de la del Prado ( ${ }^{\circ} 308$, Lienzo $1,88 \times 2,10 \mathrm{~ms})^{36}$. Posteriormente pasó a formar parte de la colección que el marqués de Salamanca poseía en el palacio de Vista-Alegre ${ }^{37}$. Es muy probable que con anterioridad perteneciera al marqués del Carpio, ya que en su inventario de 1688 figura con el número 94, en la pieza tercera del Jardín de San Joaquín, un cuadro que se dice de Pablo Veronés del «Partto de Venus», que medía una vara y dos tercias de alto por tres varas y una tercia de ancho (traducido en centímetros $139,1 \times 278,3$ ) y que se tasó en 13.300 reales ${ }^{38}$. Cuadro que a su vez, aunque se diga que medía una vara y tercia, debe corresponder al vendido en la almoneda del marqués del Carpio de 1695 a Isabel Casier por 8.860 reales ${ }^{39}$. Asimismo cabe suponer que corresponda a la obra que, con el mismo título y a nombre del mismo autor, el duque de Berwick y de Alba ${ }^{40}$ cita, procedente de la casa de Lemos, entre los cuadros que pertenecieron a la casa de Alba.

El segundo cuadro, «Cristo yacente adorado por el Papa San Pío V» $(\text { C. } 42 \times 30 \mathrm{cms} \text {. })^{41}$ (Fig. 6), firmado «O (pus) PARRHASII», es una alegoría del papel redentor de Cristo. Se trata de una obra de devoción privada, preciosista y delicada, realizada con pinceladas breves y vibrantes, en la que contrasta el ensimismamiento y serenidad de la escena principal, Pío V contemplando el cuerpo sin vida de Cristo, con el movimiento y aspecto triunfante de los ángeles del registro superior. Se conoce un dibujo de Cristo yacente, considerado de Pablo Veronés, que se ha relacionado correctamente con la figura del Salvador presente en el cuadro «Michele Parrasio adorando a Cristo muerto», también de Parrasio, que se conserva en la iglesia de San Giuseppe de Venecia, cuadro que tiene la misma composición que el del Prado, con la diferencia de que en vez de San Pío V figura el propio pintor ${ }^{42}$. Al apreciarse la influencia de Veronés no sólo en la figura de Cristo, sino también tanto en el carácter escenográfico de la representación como en los ángeles vestidos de ricas y agitadas telas, pudiera ser cierto, como dice

\footnotetext{
${ }^{34}$ Fernández Bayton, G., Inventarios Reales. Testamentaría del Rey Carlos II 1701-1703, Madrid, 1981, Vol. II, p. 285. B. Barghahn (Philip IV and the «Golden House» of the Buen Retiro, Nueva York, 1986, Vol. I, pp. 182 y 184, Vol II, fig. 714) cita el correspondiente asiento del inventario de 1701 traduciéndolo al inglés, localiza nuestra pintura en la habitación mencionada y comenta la alegoría representada.

${ }^{35}$ Fernández-Miranda, F., Inventarios Reales. Carlos III 1789-1790, Madrid, 1988, Vol. II, pp. 276-277.

${ }^{36}$ Catálogo de la Galería de Cuadros del Excmo. Sr. D. José de Madrazo, Madrid, 1856, p. 76.

${ }_{37}$ Catálogo de la Galería de Cuadros de la posesión de Vista-Alegre propiedad del Excmo. Sr. Marqués de Salamanca, s/f, pp. 75-76.

${ }^{38}$ Burke, M.B., Private collection of Italian art in the seventeenth Century Spain, Universidad de Nueva York, 1984, Vol. II, p. $252 \mathrm{f}$.

${ }^{39}$ Saltillo, Marqués del, «Artistas madrileños (1592-1850). II Pintores y Pinturas», Boletín de la Sociedad Española de Excursiones, 1953, p. 239.

${ }^{40}$ Berwick y de Alba, Duque de, Discurso de ingreso del Duque de Berwick y de Alba en la Academia de San Fernando, Madrid, 1924, p. 85.

${ }^{41}$ Museo del Prado. Inventario General de Pinturas. I..., Madrid, 1990, p. 130, $\mathrm{n}^{\circ} 430$ (inv. act. $\mathrm{n}^{\circ} 284$ ) (en la ficha del inventario de 1857 figura como obra de «Veronés (Pablo Cagliari, llamado por su pais El)» y en la ficha del inventario actualizado como de «Michele Parrasio»).

Véanse también M. Bryan, (op. cit., 1889, Vol. II, p. 254), E. Lafuente Ferrari (op. cit., 1977, p. 207) y F. Checa, (op. cit., 1994, p. 312). Ultimamente ha figurado en la exposición «Felipe II. Un monarca y su época. La Monarquía Hispánica», Madrid, El Escorial, 1998, pp. 188, $512-513$ (nº de catálogo 234).

${ }^{42}$ Véase Cocke, op. cit., 1984, pp. 172-173.
} 
Ridolfi a propósito de la mencionada pintura de la iglesia de San Giuseppe, que se basara para realizarla en un dibujo de Veronés ${ }^{43}$.

Fue entregado por Felipe II a El Escorial entre el 30 de mayo y el 2 de junio de 1576: «Una pintura sobre hoja de cobre, en que está pintado, en lo bajo, la figura de Christo muerto, hechado al largo, y el papa Pío V de rodillas, puestas las manos adorando, y en lo alto dos figuras de ángeles con un cáliz con el Sanctíssimo Sacramento en las manos, guarneçida toda de évano....; tiene de alto bara menos doçabo y de ancho media vara y dos dedos (traducido a centímetros 76,5 $\times 45,35) »^{44}$. El 1 de noviembre de 1809 fue trasladada por Quilliet de El Escorial a Madrid: «PARRASIUS Cristo en el Sepulcro» (en el cajón $\left.n^{\circ}{ }^{19}\right)^{45}$. En 1820, de nuevo en El Escorial, lo menciona Bermejo en el Camarín: «Cristo muerto, á quien adora san Pio $\mathrm{V}$, cuyo retrato se cree ser este, figuras pequeñas en cobre, de Parrasio ${ }^{46}$. Pocos años después pasaría al Museo del Prado ${ }^{47}$.

No parece encontrarse en muy mal estado de conservación. En el archivo fotográfico del Museo del Prado se conserva una fotografía antigua, que al compararla con una moderna parece indicar que el cuadro ha sido limpiado y se han reintegrado pequeñas pérdidas de pintura (obsérvese, en particular, las túnicas tanto del ángel que sostiene el brazo a Cristo como del que flota en el aire en la parte superior derecha, vestimenta del Papa, cielo). Además, en noviembre de 1998, me dijeron en el Museo del Prado que se había restaurado recientemente.

En el Monasterio de El Escorial existe una copia antigua floja, casi con toda seguridad de mano española, que reproduce el original, añadiendo al lado de Cristo una mesa vestida con un libro encima en el que está escrito: «BIBLIA SACRA» (Lienzo $130 \times 182 \mathrm{cms}$ ) (Fig. 7).

También en el Monasterio de El Escorial se halla «Las Marías en el sepulcro en busca del Señor» (L. 139,6 × 113,7 cms) (Fig. 8), obra que no ha llamado mucho la atención de la críti$\mathrm{ca}^{48}$ y que, sin embargo, lleva la firma de nuestro pintor en la base del sepulcro vacío - «OPVS PARRHASII»- y goza de un buen estado de conservación. Su composición se relaciona con la presente en la parte baja del dibujo «Alegoría de la Redención» de Pablo Veronés, que se conserva en el Metropolitan Museum de Nueva York ${ }^{49}$, dibujo en donde un sepulcro, de forma muy parecido al de nuestro cuadro, aglutina a su alrededor a algunas mujeres cuyas posturas expresan asombro y desconcierto.

Tanto el sabor veronesiano de la composición — que por otra parte nada tendría de extrañar que se basara en un dibujo de Pablo ${ }^{50}$ - como el estilizado canon que utiliza para la repre-

\footnotetext{
43 «La tauola del morto Saluatore nella Chiesa di San Gioseppe è sua pittura, nell' altare ch' egli si eresse, e vi si ritrasse à piedi in atto d'adorazione, con due Angeli in gloria, e ne trasse 1'inuentione da vn disegno di Paolo da noi veduto; e dinanzi à quello Altare, che si chiama tuttauia di Parrasio, fù sepelito.» (Ridolfi, op. cit., 1648 (edición von Hadeln (quien nos informa que esta pintura está firmada y fechada en 1573), 1924, Vol. II, p. 138).

${ }^{44}$ Zarco Cuevas, Fray J. (quien la identificó con la obra del Prado), «Inventario de las alhajas, relicarios, estatuas, pinturas, tapices y otros objetos de valor y curiosidad donados por el rey don Felipe II al Monasterio de El Escorial. Años 1571 a 1598.», Boletín de la Real Academia de la Historia, 1930, Vol. 97, p. 40.

La diferencia tan grande entre las medidas que hoy tiene el cuadro (42 x $30 \mathrm{cms}$ ) y las que figuran en la entrega (76,5 x $45,35)$ muy posiblemente se deba a que entonces se midiera con marco -que en este caso debía ser más alto que ancho-, como debió ocurrir con otros cuadros que entregó Felipe II a El Escorial (Véase al respecto Ruiz Manero, J. M., Pintura italiana del siglo XVI en España: II Rafael y su escuela, Madrid, 1996, p. 86).

45 Hempel Lipschutz, art. cit., 1961, p. 242.

${ }^{46}$ Bermejo, op. cit., 1820 , p. 243.

${ }^{47}$ En 1857 ya lo cita Poleró entre los cuadros de dicho Museo procedentes de El Escorial: «430 Jesucristo difunto, adorado por San Pio V; cobre (PABLO VERONÉS).» (op. cit., p. 180).

48 Véase Bryan, op. cit., 1889, Vol. II, p. 254 (lo cita entre las pinturas de Parrasio).

49 Véase Cocke, op. cit., 1984, p. 75, $\mathrm{n}^{\circ} 18$.

${ }^{50}$ Dice Ridolfi, a propósito de Parrasio: «Dopo la morte di Titiano si diede in tutto ad imitar il Veronese, di cui fattosi amico ne traheua continui disegni, de' quali valeuasi nelle opere sue» (op. cit., 1648 (edición von Hadeln, 1924, Vol. II, p. 137). Además, como se ha dicho, en el Museo del Prado existe una pintura de Parrasio, «Cristo yacente adorado por el Papa San Pío V» (cat. $n^{\circ} 284$ ), cuya figura de Cristo se basa en un dibujo considerado de Pablo Veronés.
}

$A E A$, LXXVIII, 2005, 309, pp. 45 a 58 

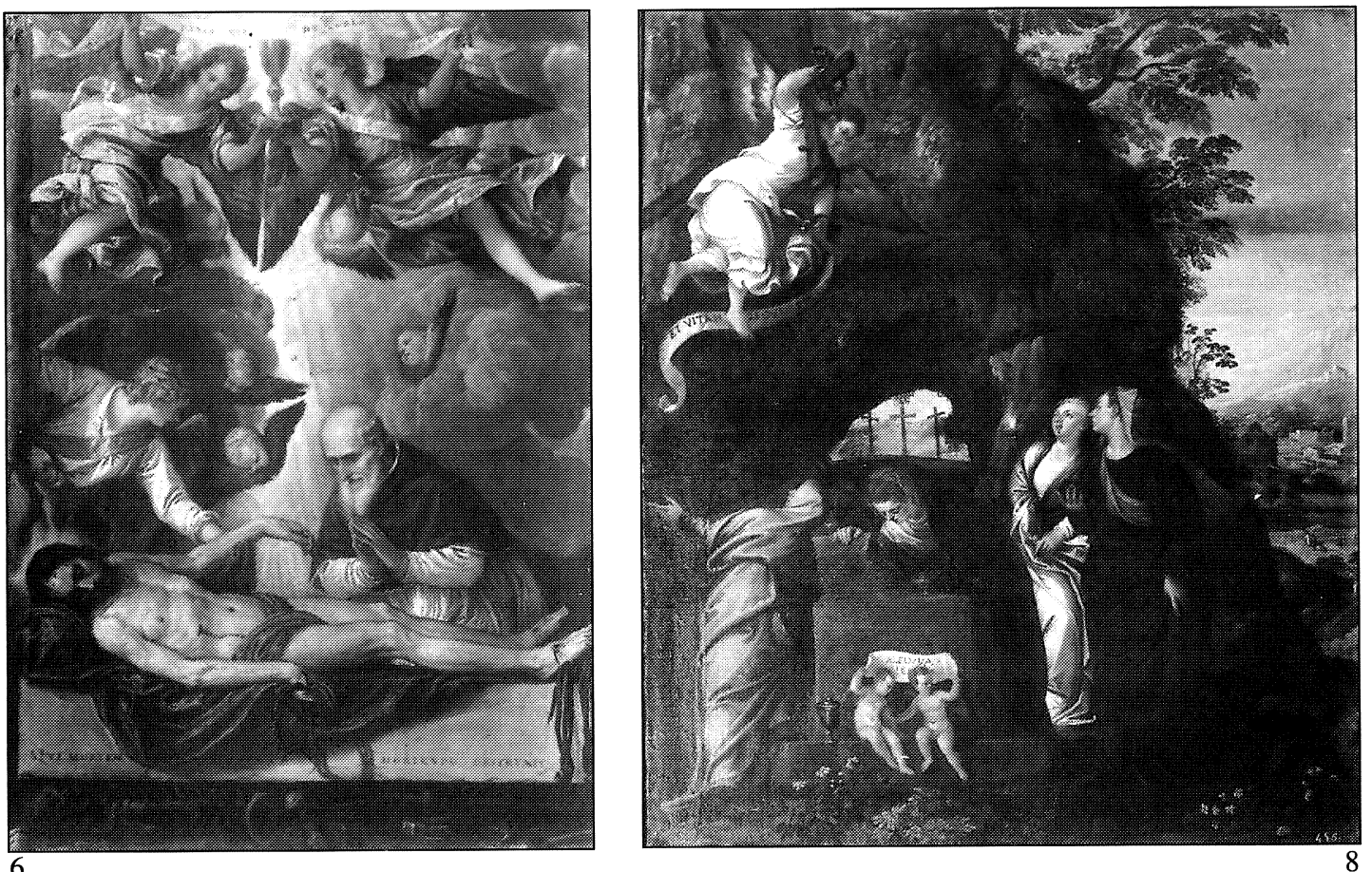

7

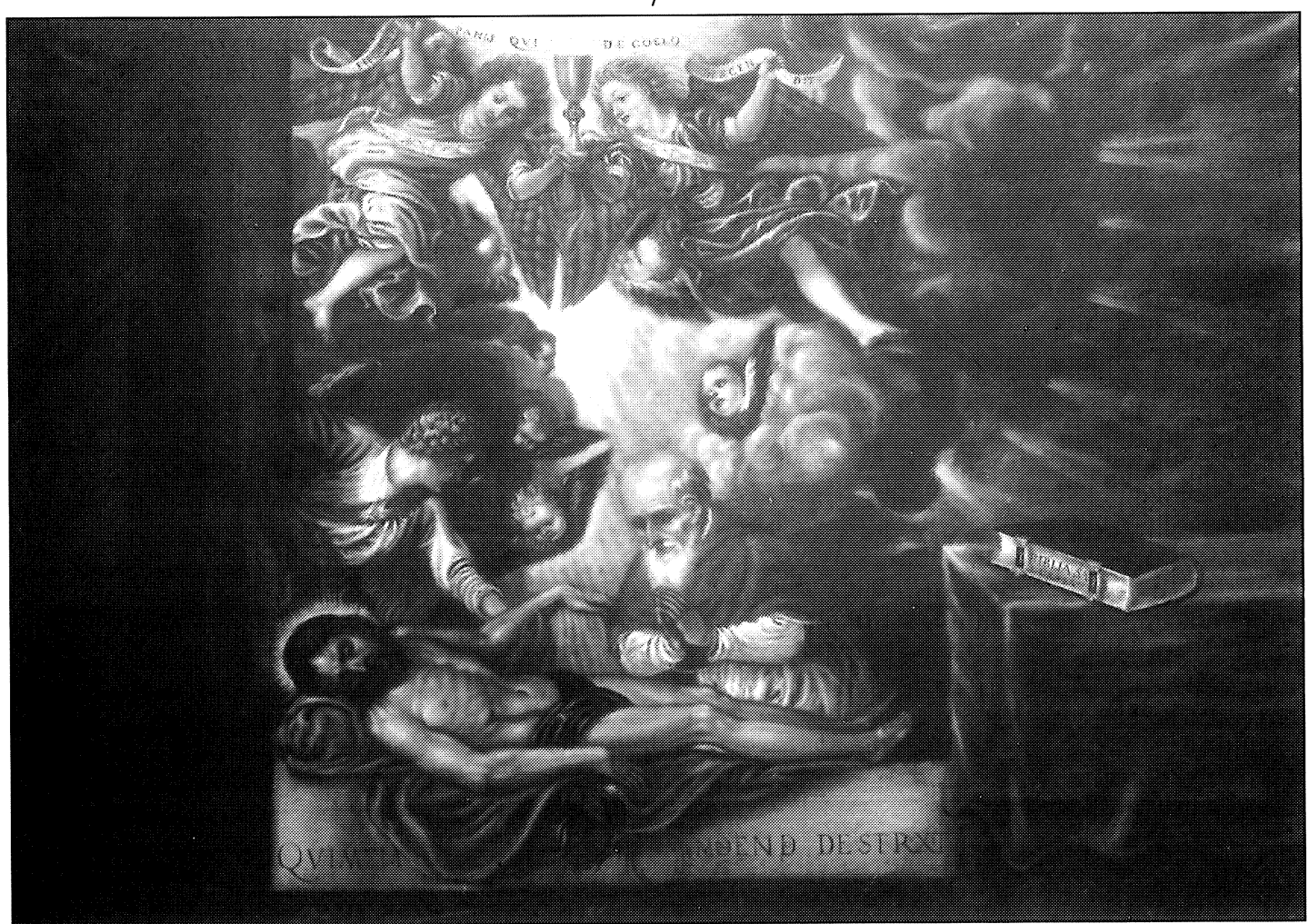

Fig. 6. Michel Parrasio: Cristo yacente adorado por el Papa San Pío V. Madrid, Museo del Prado.

Fig. 7. Michele Parrasio (copia): Cristo yacente adorado por el Papa San Pío V. El Escorial (Madrid). Monasterio. (Copyright $(\odot)$ Patrimonio Nacional).

Fig. 8. Michele Parrasio: Las Marías en el sepulcro en busca del Señor. El Escorial (Madrid). Monasterio. (Copyright () Patrimonio Nacional). 
sentación de las figuras, así como el preciosismo con el que el pincel dibuja los pliegues de las telas, nos hablan de Parrasio. En cuanto a su colorido resulta algo apagado, pues para vestir a los personajes se sirve predominantemente de grises, marrones y blancos, sin que se establezcan fuertes contrastes de color.

Fue entregado a El Escorial por Felipe II en febrero de 1577: «Otro lienço de pintura al olio de Christo nuestro Señor en el sepulchro, con las Marías y dos Angeles que tienen el sepulchro; y en lo alto otro Angel con vn letrero que dize: «Et vitam resurgendo», puesto sobre tabla, con molduras doradas: tiene de alto dos varas y quarta y (de) ancho vara y çinco sesmas (traducido a centímetros $188 \times 153,5) »{ }^{51}$. Figura entre los cuadros trasladados por Quilliet de El Escorial a Madrid el 1 de noviembre de 1809: «PARRASIO. Las tres Marías en el sepulcro.» (en el cajón número 18) ${ }^{52}$. El 14 de mayo de 1813 se llevó del exconvento del Rosario a la Academia de San Fernando: «N. 217. Vn quadro de 7 palmos escasos de alto por 5 y 4 dedos de ancho (traducido a centímetros: menos de $147 \times 112,2$ ). Representa La Magdalena y demás mujeres que fueron á buscar al Señor en el sepulcro, quando el Angel les dijo que había resucitado. Autor, Pablo Veronés» ${ }^{53}$. En 1820, de vuelta a El Escorial, Bermejo lo cita en la Iglesia Vieja: «12. Cuatro mugeres buscan á Jesucristo en el sepulcro, y un ángel en lo alto les presenta una tarjeta en que se lee: Et vitam resurgendo reparavit: en la peana del sepulcro se ven sentados dos angelitos con el aleluya en las manos, por Parrasio» ${ }^{54}$. En tiempos de Poleró se encontraba en la Sala prioral: «ESTILO DE CARLOS VERONÉS./ 456 Las Marías en el sepulcro en busca del Señor. / Es evidentemente apócrifa la firma de Parrhasio que tiene este cuadro./ Alto, 5 piés, 3 lín.; ancho, 4 piés, 1 pulg., 1. lín. (traducido a centímetros $139,6 \times 113,7){ }^{55}$.

También en El Escorial, se conserva una «Adoración de los Reyes Magos» (L. $134 \times 128$ cms) ${ }^{56}$ (Fig. 9) que a mi juicio le pertenece. En cuanto a su composición, guarda relación con la del cuadro del mismo asunto fechado en 1573 y conservado en la National Gallery de Londres, cuadro que Pignatti y Pedrocco piensan que se debe en su mayor parte a Pablo Veronés ${ }^{57}$. Comparten ambos tanto el entorno de ruinas clásicas en donde se sitúa la escena como el hecho de colocar a María encima de unas gradas y de desarrollar fastuosamente con un marcado sentido procesional la llegada de los Magos. Asimismo, manifiesta coincidencias de composición con una obra homónima conservada en la Alte Pinakothek de Munich ${ }^{58}$, véase en particular la postura de San José. Por otra parte, existe un dibujo de Pablo Veronés - conservado en el Museo Teyler de Haarlem y considerado preparatorio de la Adoración londinense ${ }^{59}$ - en el que se aprecian ideas y elementos compositivos presentes en nuestro cuadro y que Veronés no utilizó para su obra hoy en Londres. Obsérvense, al respecto, el caballo visto desde atrás, la figura inclinada de San José, el rey mago de amplio turbante colocado detrás del que se en-

${ }^{51}$ Zarco Cuevas, art. cit., 1930, Vol, 97, p. 67.

Respecto a la diferencia de medidas entre las que tiene actualmente el cuadro y las presentes en la entrega véase la nota a pie de página $n^{\circ} 44$

${ }_{52}$ Hempel Lipschutz, art. cit., 1961, p. 240.

53 V.V., «Manuel Napoli y la colección de cuadros del exconvento del Rosario», Revista de Archivos, Bibliotecas y Museos, 1905, febrero, p. 153.

${ }^{54}$ Bermejo, op. cit., 1820, p. 209.

55 Poleró, op. cit., 1857, p. 112. Ignoro los motivos que le llevaron a pensar que la firma era apócrifa, pues no me lo parece.

56 Véase Ruiz Gómez (op. cit., 1991, pp. 145-146) y Checa (op. cit., 1994, p. 295). Ambos la atribuyen a Carletto Veronese, aunque la primera con dudas, y piensan que se trata del cuadro del mismo asunto citado por Bermejo en el claustro principal alto, cuadro que creo más probable que sea el $n^{\circ} 364$ del catálogo Poleró. La identifican, como se hace en este artículo (véase más adelante), con el cuadro n 363 del catálogo de Poleró.

57 Véase Pignatti y Pedrocco, op. cit., 1995, T. II, p. 291-293.

58 Obra del taller de Veronés según Kultzen (1971), considerada variación del cuadro londinense por Pignatti, y de la que existe una copia en Dresde (cf. Pignatti, op. cit., 1976, T. I, p. 136 y T II, Láms. 465 y 466).

59 Véase Cocke, op. cit., 1984, pp. 160-161.

AEA, LXXVIII, 2005, 309, pp. 45 a 58 
cuentra arrodillado próximo a la Virgen y el Niño. Nada tendría de particular que Parrasio se hubiera valido de este dibujo u otro del mismo autor en donde aparecieran los elementos reseñados.

Pero si bien la composición tiene su origen en Veronés, el hecho de transformar su ampuloso y solemne estilo decorativo en preciosismo diminuto y gracioso pertenece a Parrasio. Construye los ropajes de sus estilizados personajes con pinceladas cortas y vibrantes, en una técnica similar a la utilizada en su «Cristo yacente adorado por San Pío V» del Museo del Prado. Asimismo, también resulta común a ambas obras las aristocráticas manos de dedos afilados y largos y la atmósfera de dulce y tierno candor que sabe recrear su autor. Frente a la opulencia decorati-

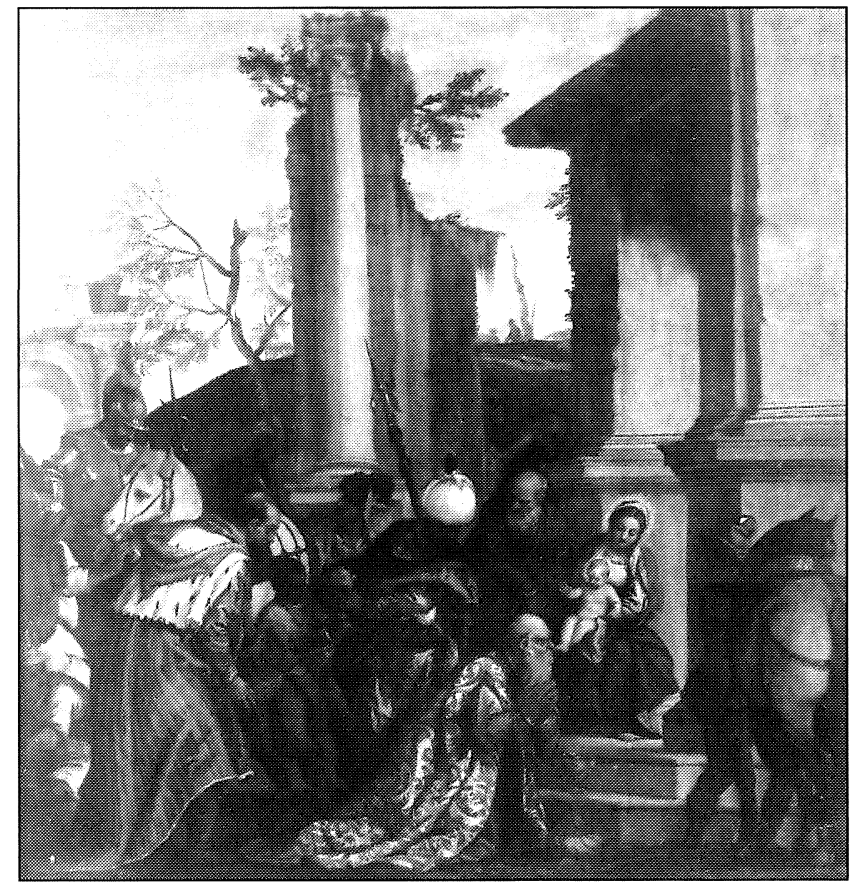

Fig. 9. Michele Parrasio: Adoración de los Reyes Magos. El Escorial (Madrid). Monasterio. (Copyright (C) Patrimonio Nacional). va del mundo de Pablo Veronés, sorprende en Parrasio la cierta infantil gracia con la que realiza sus obras.

Es muy probable que se encuentre en el Monasterio desde al menos el siglo xvir, ya que posiblemente corresponda a la siguiente pintura mencionada en 1657 por el padre Santos en la Antesacristía del Monasterio de El Escorial: «Sobre las dos puertas, que la tienen en medio, ay dos Quadros de la Adoracion de los Reyes, y quando crucificaron à Christo Señor nuestro (cuadro ${ }^{\circ} 496$ del Museo del Prado, L. $131 \times 125$ ), de Paulo Verones, que como el de enmedio, se ajustan al ancho de las Puertas, que es quatro pies y medio, y el alto quatro (traducido a centímetros $111,2 \times 125,1)$; de figuras medianas, pintadas de buen gusto, y disposicion» ${ }^{60}$. Aunque no se diga el asunto, se supone que es el cuadro mencionado en el mismo lugar en una relación anónima del siglo xvir sobre los cuadros de el Escorial publicada por Andrés ${ }^{61}$. En el siglo XVIII siguen citándola en el mismo lugar, siempre como obra de Pablo Veronés, tanto el padre Ximénez como el anónimo autor de una relación histórica de las pinturas de El Escorial por su orden riguroso de colocación hecha en 1776 y Ponz ${ }^{62}$. Muy probablemente se trate de

\footnotetext{
${ }^{60}$ Santos, op. cit., 1657, fol. $42 \mathrm{v}$.

Tanto Ruiz Gómez (op. cit., 1991, p. 146) como Checa (op. cit., 1994, p. 295) pensaron que esta mención correspondía al cuadro del mismo asunto que se conserva en el Museo del Prado (inv. act. n 489 . L. 160 x 140 cms). En cambio, parece más probable que se trate de nuestra pintura por coincidir más en sus medidas tanto con las facilitadas por el mismo Santos (en centímetros $111,2 \times 125,1)$ como con las que actualmente tiene el cuadro de la «Crucifixión» $(\mathrm{L} .131 \times 125 \mathrm{cms})$ -que se conserva en el mismo Museo y que en el presente artículo se atribuye a Alvise del Friso (inv. act. $n^{\circ}$ 496) (Fig. 2) - , con el que formaba pareja. Además, no existen indicios que permitan suponer que el cuadro $\mathrm{n}^{\circ} 489$ estuvo en El Escorial.

61 Andrés, art. cit., $1971, \mathrm{n}^{\circ} 173$, p. 56

62 Ximénez, op. cit., 1764, fol. 288.

Vega (op. cit., 1962, T. V, p. 247), quien publica la relación, cree que se trata del cuadro del mismo asunto número 364 (L. 139 x $112 \mathrm{cms}$ ) del catálogo de Poleró. Resulta más improbable dicha identificación porque sus medidas se ajustan menos a las mencionadas por el padre Santos (en centímetros 111,2 x 125,1).

Ponz, op. cit., 1788, T. II, Carta III, nº 38 (edic. 1988, Vol. I, p. 362).
} 
la siguiente pintura trasladada de El Escorial a Madrid por Quilliet el 1 de noviembre de 1809 en el cajón n ${ }^{\circ}$ 14: «PARRASIO. La Adoración de los Reyes» ${ }^{63}$. Aunque no coincidan ni las medidas ni el asunto, es muy posible que se trate del cuadro $n^{\circ} 363$ del catálogo de Poleró: «Estilo de Cárlos Veronés. 363 Nacimiento del Señor y adoración de los pastores. Alto, 3 piés, 4 pulg., 8 lín.; ancho, 4 piés, 10 pulg., 6 lín. (traducido a centímetros $94,2 \times 135,6$ )» ${ }^{64}$. Todo hace suponer que se trate de la Adoración de los Magos que Bryan cita en el Escorial al hablar de las obras del pintor Michele Parrasio ${ }^{65}$.

\footnotetext{
${ }^{63}$ Hempel Lipschutz, art. cit., 1961, p. 239.

En la misma fecha traslada Quilliet de El Escorial a Madrid en el cajón n 18: «Copia de PARRASIO. La Adoración de los Reyes» (Hempel Lipschutz, art. cit., 1961, p. 240), cuadro que desgraciadamente no se ha podido localizar.

${ }^{64}$ Poleró, op. cit., 1857, p. 94 ( $\left.\mathrm{n}^{\circ} 363\right)$. También lo cita con el mismo número Rotondo, A., Descripción de la Gran Basílica del Escorial, Madrid, 1861, p. $148\left(\mathrm{n}^{\circ} 363\right)$.

${ }^{65}$ Bryan, op. cit., 1889, Vol. II, p. 254.
}

AEA, LXXVIII, 2005, 309, pp. 45 a 58 